\title{
Synthesis and Characterization of Carbon Nanotubes Via Spray Pyrolysis Method
}

\author{
E. Uriza-Vega ${ }_{2}{ }_{2}$ M. Herrera-Ramírez ${ }^{1}$, C. López-Meléndez ${ }^{2}$, I. Estrada-Guel ${ }^{1}$, E. Martínez-Franco $^{3}$, R. \\ Martínez-Sánchez ${ }^{1}$ and C. Carreño-Gallardo ${ }^{1}$. \\ 1. Centro de Investigación en Materiales Avanzados (CIMAV). Laboratorio Nacional de \\ Nanotecnología. Miguel de Cervantes No. 120, Chih., México. \\ 2. Universidad La Salle Chihuahua, Prol. Lomas de Majalca No. 11201, Chihuahua, México. \\ 3. Centro de Ingeniería y Desarrollo Industrial (CIDESI). Av. Playa Pie de la Cuesta No. 702, Querétaro \\ México
}

Carbon nanotubes (CNTs) have a distinctive shape with a nanosized diameter and high aspect ratio [1]. Other features include excellent mechanical properties, high thermal conductivity, high electrical conductivity, etc. [2,3]. CNTs have been intensely applied to many fields, including composites, in recent years by exploiting their geometry and excellent properties [4,5]. Because of this enormous application potential, several methods have been reported for producing large quantities of quality CNTs at a low cost. Such methods include: arc discharge, laser evaporation and chemical vapour deposition CVD. Synthesis of CNTs by CVD methods have proved to be more controllable and cost efficient than arc discharge or laser evaporation methods. Spray pyrolysis is a modification of the CVD method and is extensively used for the large-scale production of multi-wall carbon nanotubes (MWCNTs) at the lowest cost.

The spray pyrolysis process was used to synthesis of multiwalled carbon nanotubes (MWCNTs), a quartz tube, used as a solution atomizer by injection syringe system. The overall tube dimensions had an internal diameter of $9 \mathrm{~mm}$ and a length of $500 \mathrm{~mm}$. A cylindrical furnace (Thermo scientific) with a high precision temperature controller $\left( \pm 1^{\circ} \mathrm{C}\right)$ heated the tubing. The solution feed time was kept constant for $15 \mathrm{~min}$ for all experiments. Fifty millilitres of toluene (J.T. Baker, 100\%) and $1.00 \mathrm{~g}$ of ferrocene (Aldrich, 98\%) were placed in a glass container. Argon (Praxair, 99.99\%,) was used as the carrier gas; a mass flow controller at $17 \mathrm{~cm}^{3} / \mathrm{s}$ regulated the flow rate. An argon/toluene/ferrocene mixture was fed into the quartz tubing after the furnace temperature was set at $800{ }^{\circ} \mathrm{C}$.

Afterwards, the black film of MWCNTs that formed at the inner surface of the quartz tubing was mechanically removed with a brush and was analyzed by X-ray diffraction (XRD), scanning electron microscopy (SEM), transmission electron microscopy (TEM) and Raman spectroscopy.

The SEM images taken from the middle section of the quartz tube after the spray pyrolisis process, the figure 1a shows a large amount of nanotubes husk (fiber morphology) and were perpendicularly aligned with the quartz tube. The lengths of the CNTs were estimated as being greater than 1300mm and figure 1 b shows SEM micrographs of randomly oriented CNT network grown at optimized conditions as mentioned before.

Based on the above results, it can be considered that spray pyrolysis method with a ratio $50 \mathrm{ml}$ of toluene $/ 1 \mathrm{ml}$ of ferrocene at $800^{\circ} \mathrm{C}$ was appropriate for preparation of CNTs. For this reason, morphologies and structures of CNTs synthesized at this optimal condition were further characterized by TEM and HR-TEM. Figure 2, shows a high magnification image of an individual well graphitized CNT, revealing that its outer and inner diameters were 39 and $9 \mathrm{~nm}[6]$. 


\section{References:}

[1] Iijima S., Nature 354 (1991), p. 56.

[2] Roche S., Ann Chim Sci Mater 25(7) (2000), p. 529.

[3] Dai H., SurfSci 500 (2002), p. 218.

[4] Kwon H et al, Carbon 47 (2009), p. 570.

[5] Zhou T et al, Carbon 48 (2010), p. 1171.

[6] The authors acknowledge to the Red Temática Nacional de Aeronáutica, Red Materiales Compuestos and Red Temática de Nanociencias y Nanotecnología (152992).
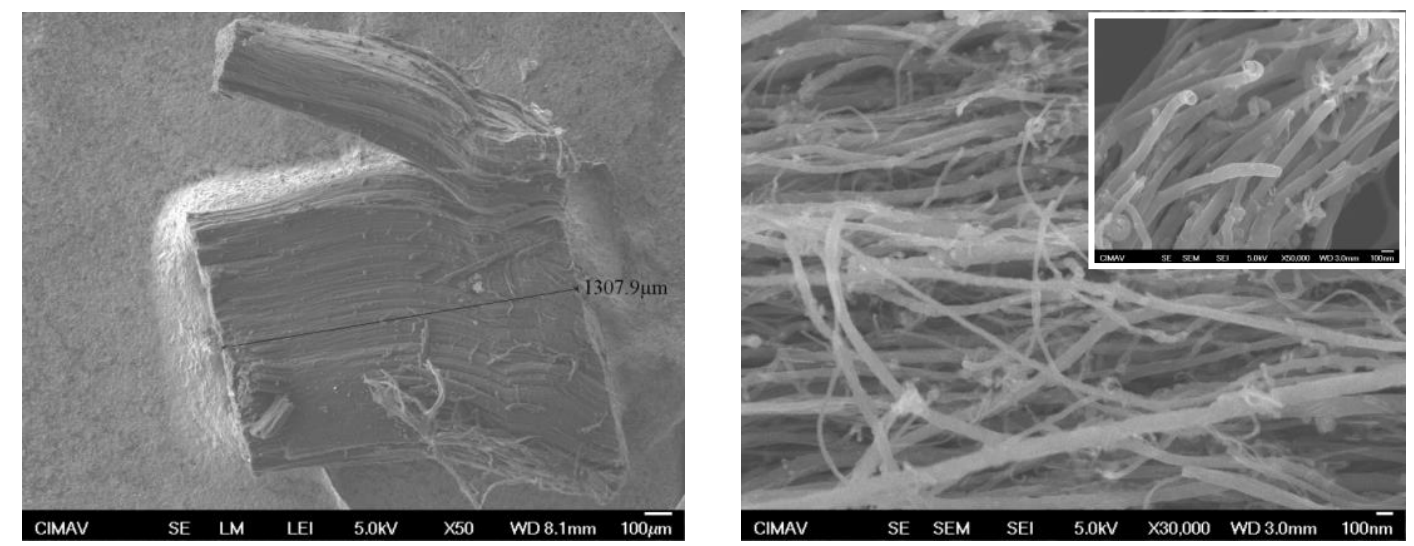

Figure 1. SEM images of nanotube films grown and the lengths of the CNTs, obtained by spray pyrolysis method

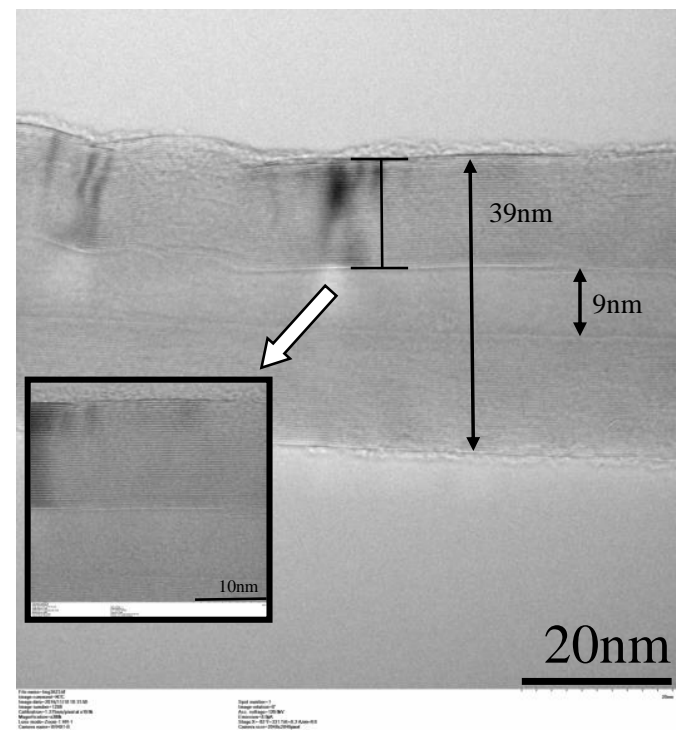

Figure 2. TEM and HRTEM images of product samples resulted from spray pyrolysis method under the optimal condition. 